\title{
Invasive mole diagnosed as vascular malformation of uterus: a case report
}

\author{
Surjyatapa Bhattacharjee, Pranoy Nath, Shabir Ahmed Choudhury*
}

Department of Obstetrics and Gynaecology, Silchar Medical College and Hospital, Silchar, Cachar, Assam, India

Received: 16 December 2020

Accepted: 08 January 2021

\section{*Correspondence:}

Dr. Shabir Ahmed Choudhury,

E-mail: sabbirc2@gmail.com

Copyright: ( ) the author(s), publisher and licensee Medip Academy. This is an open-access article distributed under the terms of the Creative Commons Attribution Non-Commercial License, which permits unrestricted non-commercial use, distribution, and reproduction in any medium, provided the original work is properly cited.

\begin{abstract}
Gestational trophobalstic neoplasia encompasses invasive mole, placental site trophoblastic tumor, epitheloid trophoblastic tumor and choriocarcinoma. Here we report a 27 year old woman with invasive mole with severe anaemia who was initially misdiagnosed as a case of incomplete abortion with vascular malfomarmation of uterus. In view of uncontrolled bleeding per vaginum, nonspecific ultrasound findings and $\mathrm{H} / \mathrm{O}$ failed dilatation and evacuation, exploratory laparotomy was decided upon and intraoperative finding was invasive mole. Hysterectomy was done.
\end{abstract}

Keywords: Invasive mole, GTN, vascular malformation of uterus, hysterectomy

\section{INTRODUCTION}

Gestational trophobalstic neoplasia (GTN) is spectrum of trophoblastic diseases that includes invasive mole, placental site trophoblastic tumor (PSTT), epitheloid trophoblastic tumor (ETT) and choriocarcinoma. ${ }^{1}$ Invasive mole constitutes $10-15 \%$ of complete hydatiform mole. It is characterized by edematous villi and overgrowth and invasion of trophoblast into myometrium, involving the peritoneum or vaginal vault. Such moles are locally invasive but generally do not metastasize distally as choriocarcinoma does. It usually originates from complete or partial mole. ${ }^{2}$ Uterine arteriovenous malformation is a comparatively rare diagnosis, most often presenting with uterine bleeding not responding to any treatment. It may be congenital but more often acquired, generally following a pregnancy or miscarriage. $^{3}$

Current study presents a case of invasive mole, initially misdiagnosed as vascular malformation of uterus with retained product of conceptus, managed with hysterectomy.

\section{CASE REPORT}

A 27 year old para 3 woman presented with on and off bleeding per vaginum and severe anemia at a tertiary care hospital. She had history of three vaginal deliveries 7 years, 4 years and 2 years back respectively. She developed bleeding per vaginum 8 months back following a period of amenorrhoea (she could not specify the exact duration). She took urine pregnancy test, which came out to be positive, following which she underwent dilatation and evacuation five times at several hospitals over last eight months. However, bleeding per vaginum continued on and off, as a result of which she developed anemia and there was history of 2 units of blood transfusion.

On examination, the patient was pale with BP 110/70 $\mathrm{mmHg}$ and pulse rate was 104/minute. Tenderness was present all over the abdomen. Per vaginal examination revealed bulky tender uterus with minimal bleeding. 
Bilateral adnexa could not be assessed properly. Urine pregnancy test was positive. Ultrasonography revealed bulky uterus of size $10.1 \times 8.6 \times 7.3 \mathrm{~cm}^{3}$ with collection measuring $6.2 \mathrm{~cm} \mathrm{x} 4 \mathrm{~cm}$ in endometrial cavity. Multiple tortuous vessels were noted in both anterior and posterior myometrium, showing vascularity on colour Doppler. MRI pelvis was done, considering the rarity of diagnosis, which again demonstrated multiple tortuous vessels in the myometrium of the uterus with intrauterine collection.

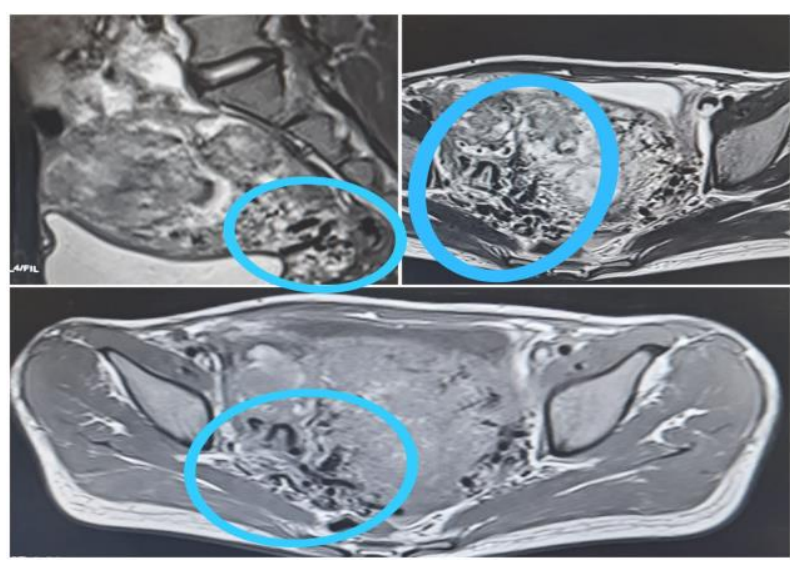

Figure 1: MRI showing multiple tortuous vessels in the myometrium (marked area).

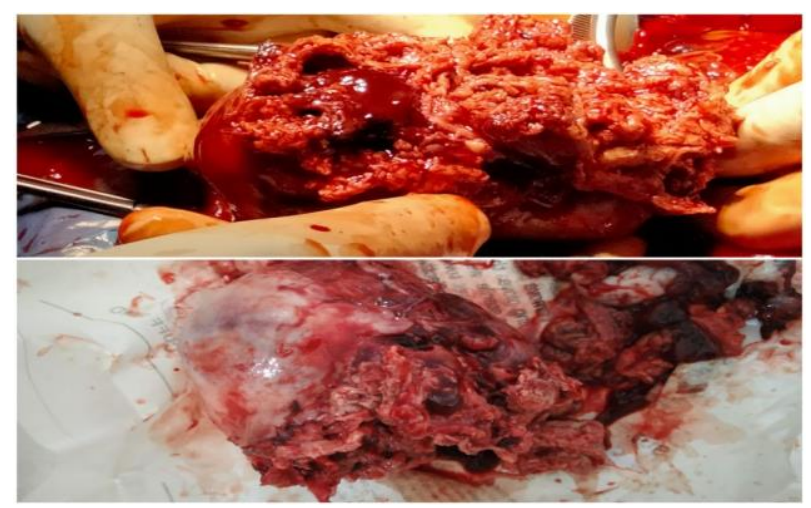

Figure 2: Intra-operative diagnosis of invasive mole.

Provisional diagnosis was made in given in favour of retained product of conceptus with vascular malformation of uterus. Hemoglobin of the patient was found to be 4.3 $\mathrm{g} \%$. Se TSH was <0.015 mIU/l, total T4 $19.10 \mu \mathrm{g} / \mathrm{dl}$, total T3 $2.95 \mathrm{ng} / \mathrm{ml}$. Chest X-ray was normal. 3 units of packed red blood cell were transfused and carbimazole and propranolol initiated.

Hemoglobin was then corrected to $8.5 \mathrm{~g} \%$. In view of failed evacuation, continued bleeding per vaginum and suspected vascular malformation of uterus, laparotomy was planned. 2 units of packed red blood cell were kept ready.

On laparotomy, intraoperative diagnosis of invasive mole was made. The trophoblastic tumour was found to perforate the myometrium in the fundal region with adhesion to surrounding pelvic wall. Total hysterectomy with unilateral salpingo-oophorectomy was done. Ovary of one side was preserved owing to the young age of the patient.

Day 1 post operative serum $\beta-H C G$ was found to be exceptionally high, 2,57,935 $\mathrm{mIU} / \mathrm{ml}$. Pathologic examination of the uterus specimen showed edematous chorionic villi with marked trophoblastic proliferation that invaded whole of the myometrium, suggesting an invasive mole.

\section{DISCUSSION}

The overall incidence of invasive mole is $1 / 15000$ pregnancies. Local invasion occurs in about $15 \%$ cases following hydatidiform mole. ${ }^{4}$ It is a form of localized gestational trophoblastic neoplasia, the usual clinical presentation being persistent vaginal bleeding after evacuation of molar pregnancy and rise in $\beta$-HCG titer. ${ }^{5}$

Abnormal proliferation of placental trophoblast with invasion into myometrium and edematous chorionic villi is the pathology behind the formation of invasive mole. ${ }^{6}$

Ultrasound is the standard aid in diagnosis of invasive hydatidiform mole which exhibits a nonspecific heterogenous or hyperechogenic focal mass with cystic vascular spaces, within the myometrium. ${ }^{7}$ Color Doppler is useful in the evaluation of angiogenesis, observed as prominent blood flow signals in various directions suggestive of arterial and venous flow. The differential diagnosis of highly vascular, intramural lesions of myometrium as noted in invasive mole includes arteriovenous malformation, and interstitial pregnancy. ${ }^{2}$ MRI may aid in diagnosis of tumour invasion but may be non-specific as well. ${ }^{7}$

The resolution of invasive moles may occur even without treatment, but this may aggravate the risks of uterine perforation and haemorrhage. ${ }^{6}$ They are highly sensitive to single-agent chemotherapy such as Methotrexate or actinomycin D. Hysterectomy is an option in patients with perforation, uncontrolled vaginal bleeding, unstable general condition, sepsis, women with completed family, and patients with extensive uterine tumor. Follow up serum $\beta$-HCG examination is done every $1-2$ weeks until 3 consecutive normal values, then continued every 3 months for 6 months after normalization of serum $\beta$ HCG. ${ }^{1}$ Invasive mole does not usually metastasize, and if it does, it is usually to lungs. ${ }^{2}$

On the other hand, uterine vascular malformation, an abnormal connection between uterine arteries and veins, is a rare cause of uterine bleeding, sometimes torrential and life threatening. It may be congenital due to abnormal embryologic differentiation of primitive vasculature. Acquired variety may occur due to disruption and defective healing of the uterine vasculature following surgical procedures such as endometrial curettage or 
cesarean section or after endometritis, pregnancy, gestational trophoblastic disease, or endometriosis. ${ }^{8}$ It may be diagnosed during postpartum period or after spontaneous abortion, surgical evacuation of the uterus for termination of pregnancy etc. ${ }^{3}$

Grayscale ultrasound may reveal non-homogenous mass with myometrial and endometrial cystic and tubular structures whereas there may be demonstration of multidirectional, high velocity flow in colour Doppler. ${ }^{9}$ (similar to that in invasive mole due to neovascularisation).

Uterine artery embolization, laparoscopy with bipolar coagulation of the uterine arteries, hysterectomy are some of the therapeutic options in management of vascular malformation. ${ }^{8}$ Demonstration of intrauterine collection in ultrasound and high velocity flow in tortuous vessels in myometrium in Colour Doppler as well as in MRI is the reason behind misdiagnosis of invasive mole as uterine malformation in our case. $\mathrm{H} / \mathrm{O}$ failed evacuation five times in the past 8 months as well as persistent vaginal bleeding led to overlap of clinical features between both the conditions. Intraoperative diagnosis being invasive mole with perforation of uterus, hysterectomy was done.

\section{CONCLUSION}

Invasive mole is a clinical entity which may be managed with chemotherapy or hysterectomy if needed. Other differential diagnosis like vascular malformation of uterus may be ruled out by a combination of biochemical method (serum $\beta-\mathrm{HCG}$ ) and ultrasound.

Funding: No funding sources Conflict of interest: None declared

Ethical approval: Not required

\section{REFERENCES}

1. Budiana ING, Pemayun TGA. Diagnosis and treatment of an atypical invasive mole: A Case Report. Biomed Pharmacol J. 2020;13(2):1548-55.

2. El-agwany AS, Abdeldayem TM, Invasive mole of the uterus: A description of two cases managed by hysterectomy. Egypt J Radiol Nucl Med. 2015;46(4): 1267-70.

3. Hashim H, Nawawi O. Uterine arteriovenous malformation. Malays J Med Sci. 2013;20(2):76-80.

4. Balagopal P, Pandey M, Chandramohan K, Somanathan T, Kumar A. Unusual presentation of choriocarcinoma: World J Surg Oncol. 2003;1(1):4.

5. Aminimoghaddam S, Maghsoudnia A. Unusual presentation of invasive mole: a case report. $\mathrm{J}$ Reprod Infertil. 2017;18(1):205-9.

6. Barber EL, Soper JT. Gestational trophoblastic disease. In: DiSaia PJ, Creasman WT, Mannel RS, McMeekin DS, Mutch DG, eds. Clinical Gynecologic Oncology. 9th ed. Philladelphia: Elsevier inc; 2018:163-89.

7. Alcazar JL. Ultrasound features of gestational trophoblastic disease. New York: CRC Press; 2018: 146-58.

8. Maj OMR, Capt LD, Maj RC, Uterine arteriovenous malformation, images, and management. Mil Med. 2015;180(1):e177.

9. Kim TH, Lee HH. Presenting features of women with uterine arteriovenous malformations. Fertil Steril. 2010;94:e7-10.

Cite this article as: Bhattacharjee $S$, Nath $P$, Choudhury SA. Invasive mole diagnosed as vascular malformation of uterus: a case report. Int J Reprod Contracept Obstet Gynecol 2021;10:800-2. 